\title{
Distress in long-term head and neck cancer carers: a qualitative study of carers' perspectives
}

\author{
Myles Balfe, Rebecca Maguire, Paul Hanly, Phyllis Butow, Eleanor O’Sullivan, Aileen Timmons, \\ Rachael Gooberman-Hill and Linda Sharp
}

Aims and objectives. To identify and describe the triggers of emotional distress among long-term caregivers (more than 1 year postdiagnosis) of people with head and neck cancer.

Background. Limited research has been conducted on the factors that cause head and neck cancer caregivers to become distressed.

Design. Qualitative cross-sectional.

Methods. In-depth semi-structured interviews. Interviews were conducted via telephone. The study setting was the Republic of Ireland.

Results. Interviews were conducted with 31 long-term caregivers (mean time since diagnosis 5.7 years, SD 2.9 years). Head and neck cancer caregivers experienced significant distress. Six key triggers of emotional distress were identified: understandings and fears of illness, lifestyle restrictions and competing demands, facial disfigurement, financial problems, comorbid health problems and witnessing suffering. Cutting across all of these individual causes of distress was a strong feeling of loss caused by head and neck cancer.

Conclusions. Some head and neck cancer caregivers became considerably distressed by their caring role. Although distress appears to decline with time for many caregivers, some continue to be distressed for years following the patient's diagnosis. It would be useful for future research to explicitly investigate caregivers' experiences of loss.

Relevance to clinical practice. Health professionals may be able to reduce distress in this group if they can help caregivers to access resources that can be used to buffer financial problems. Health professionals may also be able to reduce distress if they can work with caregivers to help them to obtain something of personal value or significance from their experience of loss and suffering.

Key words: cancer, caregiver, carer, distress, head and neck, interview emotions, loss, qualitative

Accepted for publication: 26 January 2016
What does this paper contribute to the wider global clinical community?

- Data from a large sample of head and neck cancer caregivers $(n=31)$.

- Evidence that long term head and neck caregivers can experience significant distress, and that this distress can last a considerable period of time after cancer treatment has ended.

- Evidence that a wide range of factors can cause head and neck caregivers to become distressed.
Authors: Myles Balfe, $\mathrm{PhD}$, Researcher, National Cancer Registry of Ireland, Cork Airport Business Park, Cork; Rebecca Maguire, $\mathrm{PhD}$, Researcher, National College of Ireland, Dublin; Paul Hanly, $\mathrm{PhD}$, Researcher, National College of Ireland, Dublin, Ireland; Phyllis Butow, PhD, Professor, Centre for Medical Psychology, University of Sydney, Sydney, NSW, Australia; Eleanor O'Sullivan, School of Dentistry, University College Cork, Cork; Aileen Timmons, PhD, Researcher, National Cancer Registry of Ireland, Cork
Airport Business Park, Cork, Ireland; Rachael Gooberman-Hill, $\mathrm{PhD}$, Researcher, Musculskeletal Research Unit, University of Bristol, Bristol; Linda Sharp, PhD, Professor, Newcastle University, Newcastle, UK

Correspondence: Myles Balfe, Researcher, National Cancer Registry of Ireland, Cork Airport Business Park, Cork, Ireland. Telephone: +353 (0) 214318014 .

E-mail: m.balfe@ucc.ie 


\section{Introduction}

Head and neck cancer is one of the most prevalent forms of cancer worldwide, with hundreds of thousands of individuals diagnosed with the condition each year (Mehanna et al. 2010). In 2002 the World Health Organization estimated that there were 300,000 annual deaths from head and neck cancer, with the most common sites being the oral cavity, the larynx and the pharynx (Mehanna et al. 2010). The male to female ratio for head and neck cancer ranges from 2:1-15:1 depending on the location of the cancer (Mehanna et al. 2010). Most cases occur in individuals over 40 years of age and alcohol and tobacco use have traditionally been the main causal factors. Head and neck patients and their families, are often from disadvantaged life circumstances (Mehanna et al. 2010, Chen et al. 2014). Increasingly, other risk factors are being identified, including the Human Papilloma Virus (HPV). Patients who develop head and neck cancer as a result of HPV are usually younger and often do not report the usual risk factors of smoking or high alcohol intake (Mehanna et al. 2010). Head and neck cancer is associated with substantial morbidity; it can cause disfigurement and as a result of medical treatment lead to substantial difficulties with eating, swallowing and speaking (Fletcher et al. 2012). It thereby has the potential to seriously undermine an individual's quality of life. In Ireland, it has been estimated that head and neck cancer can lead to productivity losses of 253,000 Euro per person, mainly as a result of premature mortality (Pearce et al. 2015).

Many people diagnosed with head and neck cancer are supported and looked after by friends or family members (collectively referred to as caregivers or caregivers). Survivors often benefit from the support and understanding offered by their family and friends (Fletcher et al. 2012, Parker et al. 2014). While caring for someone with a health problem can be rewarding, it is also something that comes with its own challenges (Chambers et al. 2001, Vaskill et al. 2010). Studies have found that cancer caregivers, like caregivers in relation to any condition that has substantial impacts, and especially head and neck caregivers, experience high levels of psychological distress (Pitceathlya \& Maguire 2003, Drabe et al. 2008, Jayani \& Hurria 2012, Longacre et al. 2012). Distress can be defined as the emotional burdens, stressors and frustrations that stem from supporting someone with cancer, a severe, complex, condition (Haman 2008) and may be caused or 'triggered' by multiple factors. Verdonck-de Leeuw et al. (2007) discovered that $20 \%$ of the spouses included in their head and neck cancer study reported clinically significant distress. In their study of 143 caregivers, Ross et al. (2010) detected high levels of distress in $37.5 \%$ of a sample of caregivers 6-24 months postdiagnosis. Other studies that have used standardized structured interviews have found that $14.7 \%$ of head and neck caregivers experience depression, and 13\% adjustment disorder (Lee et al. 2015). Head and neck caregivers may in fact be more distressed by head and neck cancer than the patients themselves (Richardson et al. $2015 a, b)$. Around a third of head and neck cancer relative/ friends indicate that they believe that caring is a significant burden on caregivers (Precious et al. 2012). Distressed head and neck caregivers report high levels of unmet need (Chen et al. 2009, 2014).

\section{Background}

Previous research (primarily quantitative) has linked a number of factors with distress in cancer caregivers both generally and in head and neck specifically, including: the presence of feeding tubes and having fewer social contacts (Verdonck-de Leeuw et al. 2007); patient symptoms (e.g. inattention, apathy, agitation, slowed behaviour) (Bond et al. 2014) and dysphagia (Nund et al. 2014); lack of medical/nursing training (Penner et al. 2012); financial concerns and fear of recurrence (Nijboer et al. 1999, Given et al. 2001, Mohammed et al. 2015); greater amount of time spent caring, higher level of relative/friend needs and uncertainty about the future (Longacre et al. 2012).

Despite the research mentioned here, researchers (Donnelly et al. 2008, Longacre et al. 2012, Chen et al. 2014) have also noted that, overall, relatively little attention has been paid to the psychological health of head and neck cancer caregivers. This is especially the case for caregivers who are no longer in the early phases of the posttreatment illness trajectory (Ross et al. 2010). In particular, few qualitative studies have sought to access these caregivers' own perspectives on their psychological health (Roing et al. 2008). The lack of qualitative research here is important because while quantitative studies can detect associations between distress triggering factors and head and neck cancer caring, they do not necessarily explain the underlying reasons for these associations. Identifying the causes of head and neck caregivers' distress is important both to inform service development and to better meet these caregivers' needs.

\section{Aim}

The aim of this study was to identify and describe the triggers of emotional distress among long-term caregivers for people with head and neck cancer. 


\section{Method}

\section{Design}

This qualitative cross-sectional study was a component of a larger project that explored the post treatment outcomes of head and neck caregivers in Ireland. For that larger project, 197 caregivers answered a questionnaire that explored (1) their experiences of using healthcare services and (2) their unmet needs (Pearce et al. 2015). Caregivers were eligible to take part in the study if they had been caring for relative/friend with head and neck cancer for a minimum of 1 year. At the end of the questionnaire we asked caregivers for permission to recontact them to participate in subsequent research. One hundred and sixty caregivers agreed to be recontacted, all of whom were subsequently invited, by letter, to be interviewed (see Fig. 1). To minimize the risk of attrition all caregivers were sent a reminder letter about the study 2 weeks after the initial contact letter. For ethical reasons (stipulated by ethics' committees), we were not permitted to offer caregivers' incentives to take part in the study. A total of 31 caregivers ultimately replied, all of whom were interviewed.

Ethical approval was provided by nine local University ethics committees (all of the hospitals who treated the relatives/friends who caregivers were caring for).

\section{Data collection}

In-depth interviews were identified as the ideal method, because we wanted to investigate caregivers' accounts and experiences in detail. The first author conducted all interviews by telephone. The first author was a $\mathrm{PhD}$ Lecturer in Sociology who had previously conducted more than 250 qualitative interviews and had published more than 30 peer-reviewed journal articles. Telephone interviews were chosen because many caregivers were living across Ireland in places that would have been very difficult for the interviewer to access. The authors were also aware that telephone interviews had previously been used in Irish qualitative health studies, and were recognized as an efficient and effective away to collect high quality data (Balfe et al. 2014). Interviews lasted 31-84 minutes and all interviews were conducted in 2015.

Prior to each interview beginning, caregivers were verbally given further information about the project and what participating in it would practically entail (the average length of the interview and the types of questions that the interview would cover). Caregivers were informed that they could stop the interview at any point. They were told that the interviews would be audio-recorded, and that the interviews would be written up and reported in an anonymous format. Interviewees were asked to for agreement to audio-recording.

\section{7 carers filled in questionnaire}

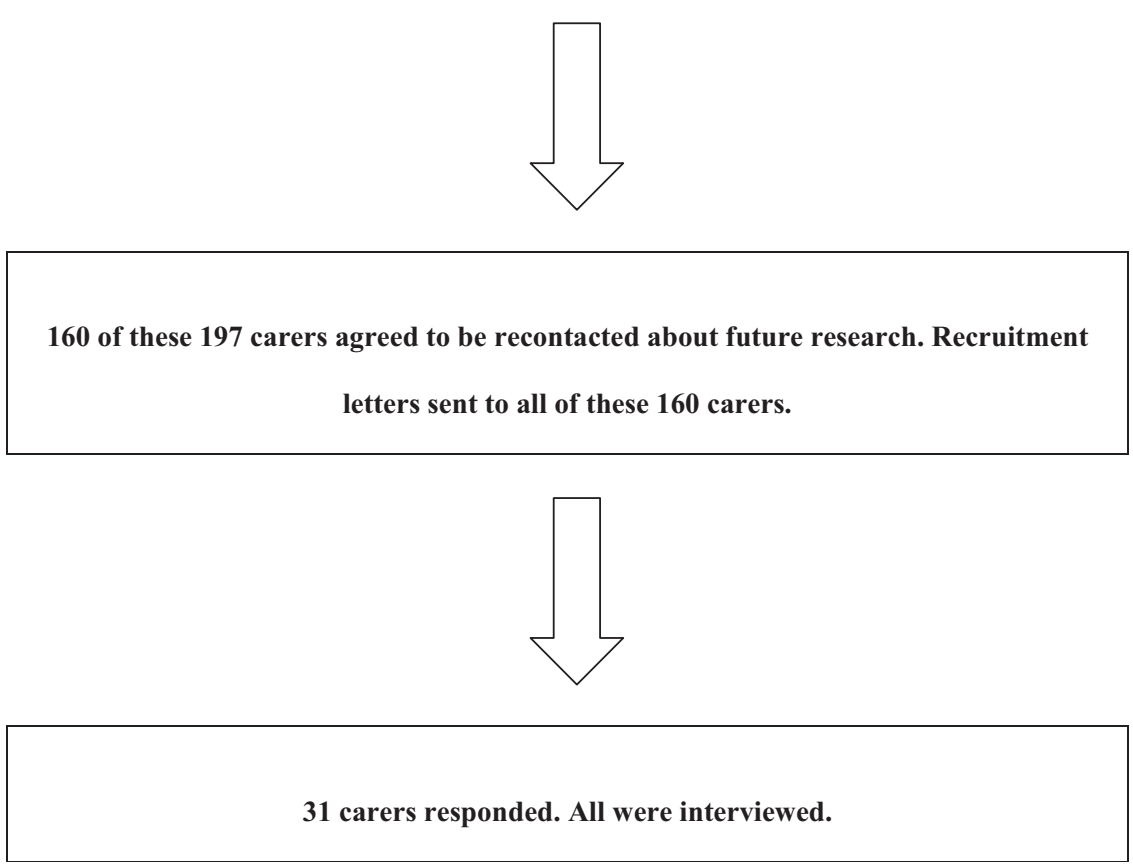

Figure 1 Flow chart outlining study recruit31 carers responded. All were interviewed. ment process. 
The interviews were semi-structured and guided by a topic guide, which was divided into two main sections. The first two section examined caregivers' unmet needs. The second section investigated caregivers' experiences of emotional distress as a result of caring for someone with head and neck cancer. We did not seek to clinically quantify or diagnose caregivers' distress. This paper reports the results from this section of the topic guide.

Data saturation (that is the point where no new themes emerged from the interviews) was reached at interview twenty-five (Morse 2000). Interviews after this point served to corroborate themes that had previously emerged. The overall sample size (31 caregivers) is within best practice guidelines for studies based on semi-structured qualitative interviews (Morse 2000).

\section{Analysis}

The analytic approach was thematic content analysis. Interviews were analyzed in a word-processing package. The first author coded the first ten interviews and the other authors provided feedback. This was done to enhance the trustworthiness and integrity of the analysis. The first author then coded the remainder of the interviews. Analysis for each interview began by 'open coding' the interview transcript, giving each section of the transcript that addressed a particular issue a descriptive tag or 'code'. These codes were then compared and contrasted within and across interview transcripts to determine if some of them could be subsumed under high level concepts or 'categories'. These categories formed the main sections of the analysis (understandings of illness, facial disfigurement etc.). All of these themes were generated inductively from the data: for example, prior to the interviews commencing we did not anticipate that financial problems, for example, would emerge so strongly in participants' accounts as distress triggering factors. The article's presentation confirms to the consolidated criteria for reporting qualitative research (Tong et al. 2007).

\section{Results}

Interviewees' demographical characteristics are outlined in Table 1 . The majority of caregivers were female. The average length of time that interviewees had been caring (i.e. the time between the patient's diagnosis and the time of the study interview) was 5.7 years (SD 2.9 years).

The thematic content analysis revealed six key triggers of emotional distress: understandings and fears of illness,
Table 1 Interviewee characteristics

\begin{tabular}{|c|c|c|}
\hline Interview sample $(n=31)$ & Freq. & $\%$ \\
\hline \multicolumn{3}{|l|}{ Gender } \\
\hline Male & 7 & $22 \cdot 58$ \\
\hline \multirow[t]{2}{*}{ Female } & 24 & $77 \cdot 42$ \\
\hline & Mean & SD \\
\hline \multirow[t]{2}{*}{ Age } & $60 \cdot 1$ & 9.4 \\
\hline & Freq. & $\%$ \\
\hline \multicolumn{3}{|l|}{ Children } \\
\hline No & 2 & $6 \cdot 45$ \\
\hline Yes & 29 & $93 \cdot 55$ \\
\hline \multicolumn{3}{|l|}{ Highest level of education } \\
\hline High school & 19 & $61 \cdot 29$ \\
\hline University & 12 & $38 \cdot 71$ \\
\hline \multicolumn{3}{|l|}{ Employment status } \\
\hline Unemployed & 16 & $51 \cdot 61$ \\
\hline Paid employment & 8 & $25 \cdot 81$ \\
\hline Looking after family & 7 & $22 \cdot 58$ \\
\hline \multicolumn{3}{|l|}{ Private health insurance } \\
\hline No & 14 & $45 \cdot 16$ \\
\hline Yes & 16 & $51 \cdot 61$ \\
\hline Unanswered & 1 & $3 \cdot 23$ \\
\hline \multicolumn{3}{|l|}{ Medical card } \\
\hline No & 14 & $45 \cdot 16$ \\
\hline Yes & 17 & $54 \cdot 84$ \\
\hline
\end{tabular}

N.B. Medical cards entitle the bearer to free medical care in Ireland. Medical cards are means tested individuals who possess them must be below a certain income threshold.

lifestyle restrictions and competing demands, facial disfigurement, financial problems, comorbid health problems and witnessing suffering. Cutting across all of these individual causes of distress was a strong feeling of loss caused by head and neck cancer. In the following section, illustrative quotes from the interviews are indented; each interviewee's identifier is given in brackets after each quote. The format for the interviewee identifier is: (unique study identifier/interviewee's age/ interviewee's gender/their relationship with the patient).

\section{Emotional distress}

Caregivers reported high levels of distress as a result of head and neck cancer and caring. One caregiver, for example, said that:

I had a nervous breakdown on my feet. (1770/54/female/married)

Others noted about head and neck cancer:

It is very hard to deal with. (2260/51/female/married) 
You're both diagnosed with it because although you don't feel the pain or suffer the inconvenience, you still suffer in certain but in different ways. (62/44/female/married)

Words that caregivers commonly used to describe their experiences included 'shock', 'stressful', 'bad' and 'dreadful'. Some caregivers said that they were most distressed around the time of diagnosis and treatment:

You know in the beginning, I remember thinking "Oh Jesus, I'll never get through this”. (723/mid 60s/female/married)

Other caregivers said that their emotional state was tolerable during the period of diagnosis/treatment but then worsened over time as the long-term impacts of the condition became revealed. Some caregivers noted they could be distressed for considerable periods of time:

It was just so difficult. It's so stressful. And I'll say, even though we're so far down the road it's still a worry. (629/63/female/married)

The first three years were worse, they were awful. It's changed our lives completely and utterly, and not for the better, I have to say. (1412/56/female/married)

Caregivers' distress often mapped closely on to relative/ friends' conditions, so that distress generally decreased if relative/friends gradually '[went] back to normal' (1770/54/ female/married), and increased if the relative/friend's condition deteriorated:

To me this was our life ruined. But it wasn't, we got over the thing and he went back to work. But at that time I never thought we'd be back to a normal family again. (1770/54/female/married)

Emotional distress understandably had a negative impact on caregivers' health:

I'm grossly overweight, but that's my answer to stress. Whereas he hit the bottle, I hit the grub. (1744/76/female/married)

I was not sleeping, I was not eating. I lost about over a stone [in] weight. I used to pretend to eat and I nearly vomited back up. I was totally stressed out. (1770/54/female/married)

\section{Understandings and fears of illness}

There were a number of reasons why caregivers became distressed. One had to do with the understandings of illness or illness beliefs that caregivers had. Interviewees often made associations between cancer and death, for example, linking their relative/friend with other people who they knew had developed cancer and died:
On the negative side, there have been people in our own area who have lost the cancer battle. And all with that causes huge anxiety. (1416/59/female/married)

You meet people, socially or you know, on your own usually and they'd say, "oh, I had an aunt who had such and such, she's dead." (1019/54/male/married)

Some caregivers, when told of the diagnosis, imagined catastrophic futures where they would be without their partner:

I was thinking I'm going to be widowed with two small children how am I going to cope. (629/44/female/married)

Fears about head and neck cancer recurrence were common, even among caregivers whose relative/friend was years past diagnosis. Caregivers noted that they often adopted an attitude of 'anxious monitoring' in relation to their relative/ friend, where they would constantly monitor their health for signs of recurrence. As with the intensity of distress more generally, the strength of this fear appeared to vary by time since diagnosis, with a longer time since diagnosis being generally associated with less powerful fear of recurrence. Caregivers whose relative/friend was recently diagnosed regularly thought about recurrence and death; caregivers several years out from diagnosis reported a reduction in the level of anxiety, though events such as clinical visits and onset of health problems could being renewed apprehension:

I would say that this cancer thing... it does recede a little bit, but it's always there, and every time anything happens -the whole thing comes back again. And that for me would be absolutely horrific. (2270/70/male/married)

I used to think about it a lot, and it used to give me nightmares as well at times. Both of us just live with it now. But it's very hard, because every little thing... you are just living with a time bomb. (1412/56/female/married)

Four caregivers indicated that their relative/friend's head and neck cancer recurred. These caregivers were not only distressed but also fatalistic and philosophical about recurrence. Several caregivers' indicated that they possessed a finite amount of resilience, that although they could emotionally handle head and neck cancer once, they struggled to do so if it recurred:

It was the cancer back. The result of that was a complete laryngectomy. That was a desperate job altogether. That was tough, very tough. It was tough for a long time after and it's still tough. To get that bombshell again. That was terrible. I kind of went into a depression myself. And finding it so lonely, that's all I can explain it as, a desperate loneliness. (2048/51/female/married) 
The week before Christmas he went in for the result of the PET scan and he never came out. He's in there ever since [begins crying] ... So I just knew it was forever and there was nothing we could do. I kind at that stage felt, 'well I suppose we're lucky that he's still here with us.' (723/mid 60s/female/married)

Anxieties about death and cancer were not just future orientated. Head and neck cancer could also trigger memories of previous noncancer related death feelings and anxieties:

I lost my father when I was fourteen and my mother when I was eighteen and I built a defence up, so head and neck cancer slithered back to me, it brought a lot of stuff back that I had probably buried and never really addressed. (1770/54/female/married)

\section{Restrictions and competing demands}

Head and neck cancer treatment, its side effects and longterm impacts, tended to restrict caregivers' lives and thereby distress caregivers. This was particularly the case in the initial months following treatment, though some caregivers experienced permanent diminishment of their former lifestyle. For example, caregivers described how they had reduced the frequency of dining out or socializing since diagnosis of cancer, explaining that this was because of difficulties with relative/friends' abilities to chew and swallow. Many had to spend considerable time trying to figure out what relatives/friends could safely eat at home, and described this as frustrating. Caregivers indicated that they were often afraid to leave the house in case something bad happened to their relative/friend, and that they felt anxious if the relative/friend left the house without them. In general, head and cancer limited caregivers' ability to act spontaneously and freely:

And also, because of the treatment as well, his swallow has become very, very small, and we've had, I'd say the last couple of years, he's had about three serious choking fits. It was frightening. But consequently, we don't go out to eat anymore, which has a huge impact because that to me, and on him, dining out and having meals together with family and with me, you know, going out, that's all stopped. And that's so sad. It's so, so sad. (1412/56/ female/married)

I'm always worried. He's gone to town on the bus today and I'm worried that I could get a call. (1696/66/female/married)

Caregivers furthermore indicated that they also frequently had to deal with competing demands on their time and attention, especially during the early weeks and months following diagnosis. For example, they might need to attend cancer related clinical appointments while also need- ing to look after or collect older parents or children. Being pulled in different directions in this way was a considerable stressor:

That is a hard time, that is a hard time because you feel that you are a piece of elastic all the time. (591/69/female/married)

\section{Facial disfigurement}

Surgery resulted in facial disfigurement for several relative/ friends. This was often distressing for caregivers, with different caregivers noting:

It is a real shock to see somebody with half a face missing. (591/ 69/female/married)

The change in his appearance, it was awful. It was absolutely awful. (1412/56/female/married)

Some caregivers said they felt it was difficult to go out in public with the relative/friend and spoke about attracting negative attention from passersby. Different caregivers described situations where people on trains and in crowds would stop and stare at them (caregiver and their relative/friend), or sometimes make comments about them as they were walking by. Concerns about attracting unwanted attention could lead relative/friends and caregivers to restrict themselves spatially, for example, staying at home to avoid the attention of other people:

Going out in public for the first time was very strange I guess it's just other people's reactions to it. Yes, women especially, because I guess they are the vainer sex, would stare quite openly and make very loud comments, they were shocked by it. So, yeah, they were pretty horrible. (591/69/female/married)

One caregiver expressed a fear that continued medical treatment years after the initial diagnosis would gradually undermine his wife's appearance, something which would have a serious negative impact on her mental well-being:

I'm very good up to now, but one of my greatest fears would be to lose X, though probably even worse than that would be for her to just be more and more disfigured, in operations and that sort of thing, which would be so terrible for her. (2270/70/male/married)

\section{Financial problems}

Financial problems were common and also a source of considerable emotional distress. Relatives/friends, particularly those who were self-employed, often had to give up their 
jobs as a result of their cancer. This could happen either because they were either too physically weak to return to work (during or after treatment), or because the side effects of the cancer treatment such as alteration to speech or appearance-prevented them from being able to work. Caregivers could also have to give up work to look after their relative/friend, or to leave work for noncancer related reasons such as reaching retirement age. Simultaneous with this loss of income, caregivers' ongoing expenses often increased, for example because they had to pay for additional medications and treatments, special foods treatments, home help etc. Financial problems were stressful not only in and of themselves, but also because they prevented caregivers from being able to access places and experiences-such as eating out or going on holiday that might otherwise have helped improve their well-being:

The financial problems did [have an emotional impact]. Yes, it did. We had a mortgage, we were running two cars at the time, and because I was working part-time, and I needed cars to get the kids from A to B. It was very tough. (2171/53/female/married)

You don't get holidays. You don't have money to do anything. You just live from week to week. Big changes, like you have to give up the car, give up the health insurance. (2260/51/female/married)

\section{Negative life events}

Caregivers frequently noted that negative life events, either separate to or stemming from the cancer, often distressed them as much as the cancer itself. Examples of the types of problems experienced included children having acrimonious divorces, close friends and family members dying, parents developing dementia, alcoholism and other family members developing cancer. Some caregivers said that as their relative/friend's condition improved over time, head and neck cancer often became less important as a source of worry and distress, and these other negative life events became more important. Others highlighted that these negative life events often made life situations that were made bad by head and neck cancer even worse:

I keep thinking, "What else has He got ready for me up there? What else is he going throw at me?" and my mother had a saying that, "He always sends crosses to those what can handle them". Well, I wish he'd back off because I've had enough testing. I often feel I should have stayed single [laughter]. (1744/76/female/married)

Caregivers said that their friends/relatives with head and neck cancer often experienced depression at some point post treatment, and that this was often particularly difficult to deal with. Some caregivers noted that they felt angry and frustrated at their relative/friend for becoming depressed, and then felt guilty for experiencing these emotions:

He's not the man he was put it that way. That's the only thing I can say. As I say, that's had a huge impact on my life, basically, but I don't see any way of there's no way round that, there really isn't, not as far as I know. I actually felt quite guilty because I would get cross in myself with him. But then he'll talk to me and tell me how he's feeling, the effect it's had on him, and I do understand as well where he's coming from. (1412/56/female/married)

\section{Seeing the other person suffer}

Finally caregivers became distressed from seeing their relative/friend suffer. Caregivers spoke of head and neck cancer as something that dismantled relative/friends. Witnessing that dismantling, and the physical, mental, emotional and existential pain associated with it, was traumatic, particularly when caregivers felt that there was little that they could do to prevent it:

I'm going to be real about this, I think what's upsetting for me is the fact that she, that she's lost that joy, it is quite difficult to see that being taken away from her. You get... you're kind of sad about that. (2270/70/male/married)

You're watching someone that is suffering, a good person and you wonder like what, "what good?", what purpose is it there to put that on somebody? (1019/54/male/married)

\section{Loss}

Cutting across all of the individual themes was the overarching theme of loss. As can be seen from the narrative extracts in the preceding sections, loss was articulated in multiple dimensions. Interviewees talked about loss of body image and function. They spoke about lives lost from cancer, about lost fathers and lost husbands. Caregivers mourned the lost faces of the person they cared for, loss of their social lives and freedom, lost financial security, lost holidays, lost joy, lost hope and lost futures. They also spoke of relative/friends and relatives who were lost to cancer, either physically through hospitalization or psychologically through depression.

\section{Discussion}

Researchers (Drabe et al. 2008, Ross et al. 2010, Longacre et al. 2012, Shahi et al. 2014, Mohammed et al. 2015) 
have noted that to date very few studies-particularly qualitative ones- have sought to examine the psychological wellbeing of head and neck cancer caregivers. This study therefore investigated the factors that induce distress in those caring for Head and Neck Cancer (HNC) survivors on a long-term basis. Interviews identified six key triggers of emotional distress, namely: understandings and fears of illness, lifestyle restrictions, facial disfigurement, financial problems, negative life events and witnessing suffering. These findings support the limited previous work that has been conducted on distress and head and neck cancer caregivers, and also support the idea that head and neck cancer can present 'a dark picture' for caregivers (Schaller et al. 2014).

The financial problems detected by the study were notable, and are similar to findings previously identified by East Asian researchers. Chen et al. (2014), for example, examined the unmet needs of a sample of head and neck caregivers in Taiwan. Chen $e t$ al. found that many caregivers experienced significant financial problems as a result of their relative/friend's diagnosis, mainly because their relative/friend - who was usually the principal financial provider for the household - could no longer work. Other researchers have also noted that family caregivers can experience financial difficulties because of their caregiving responsibilities (Jayani \& Hurria 2012). Our study indicates that financial problems are not only problematic in and of themselves for head and neck caregivers, but also because these problems can lead to caregivers becoming emotionally distressed. One relatively straightforward policy solution to combat distress in this group may therefore be to provide them with access to resources that can allow them to buffer financial problems. This could be done in a number of ways. For example in the Irish context, caregivers could be provided with what are called 'medical cards', which are means tested documents that entitle the individuals who possess them to free medical care, thereby reducing their ongoing expenditure. Alternatively, caregivers could be allowed to access state benefit systems to supplement-even to a modest extent-their incomes. Caregivers, as well as their relative/ friend, should also be put in contact with social services that can advise them about accessing entitlement benefits. Debt management advice may also have positive social and psychological consequences for caregivers (Timmons et al. 2013). While household finances may appear to be outside the remit of healthcare professionals, even acknowledging the financial difficulties that cancer causes may be enough to reduce caregivers' distress, and may strength the relationship between the caregiver and the healthcare team (Hanratty et al. 2007).

The strength of the association that some caregivers made between cancer and death was notable, as was the stigmatizing reactions that some reported experiencing from other people in their community. Both of these items point to a possible information vacuum, both in the wider community and also possibly within caregivers themselves. It may be useful for health professionals to talk to caregivers to determine what beliefs they hold about cancer; and to intervene to correct those beliefs if they are based on a misunderstanding of cancer and its prognosis. Caregivers and patients value psychosocial support and contact with healthcare professionals (Offerman et al. 2014, Schaller et al. 2014). Healthcare professional intervention to address informational needs may therefore correct a negative (addressing informational deficiencies and thereby facilitating emotional well-being) while also being a valuable method of support in and of itself (Fronczek 2015). This type of informational intervention should ideally be delivered early after the patient's diagnosis, and preferably face to face (Richardson et al. 2015a). It is also important for health professionals to be conscious that some caregivers may be uncertain about how to talk to professionals, and professionals may therefore may need to proactively bring up these discussions with caregivers (Longacre et al. 2015). Similarly, it may be necessary for health professionals to engage with the media to increase social understanding of head and neck cancer and its impacts. Increased awareness of the condition would help to reduce stigma around it, and may also help to reduces caregivers' fears that they could experiencing stigmatizing reactions from others as a result of their relative/friend's disfigurement. It may be useful here for health professionals to work with cancer charities and similar nongovernmental organizations when seeking to raise the 'profile' of head and neck cancer disfigurement. These organizations may be able to significantly extend the communication reach of professionals, for example, through traditional and social media (Chou et al. 2009).

The overarching theme of loss that was identified by the study was notable. 'Loss of self' is something that is often experienced by people with chronic illnesses (Charmaz 1983). Loss of self stems from the restrictions caused by illness, and the limitations that illness places on relative/ friends' freedom of action. These restrictions offer people who are ill few opportunities to construct valued selves and lives. Illness also limits opportunities to develop social relationships and can lead people with chronic conditions to develop discrediting self-definitions. While loss of self as a concept was developed in relation to people with chronic conditions such as cancer, the findings of this study suggest that it also has relevance for the people who care for those people. In fact, taken together the results of this study sug- 
gest that the single most important reason why caregivers become distressed by head and neck cancer is that the cancer leads them to a profound 'loss of self', a loss of the self that caregivers used to be, the worlds and things to which they were attached, the people who they were connected to and the futures to which they aspired. In some ways, this loss may be more corrosive for caregivers rather than relative/friends, because caregivers often need to keep their loss secret and 'put on a brave face' to help the relative/friend heal and transcend their own loss of self.

Understanding the role of loss in head and neck caregivers' narratives is a key to understand their experiences. It is also a key to understand how to health professionals can effectively intervene to help these caregivers manage their distress. Researchers have argued that individuals constantly ascribe, or at least struggle to ascribe, meaning to the events that they experience (Harvey \& Miller 1998). For example, one interviewee in this study noted that he questioned why his wife would suffer in world that was supposedly governed by a good God. People are especially likely to become distressed when the stressor that they are experiencing, such as cancer, seems senseless or meaningless to them. Davis and Nolen-Hoeksema (2001) have argued that a key function for health professionals who work with clients experiencing loss is therefore to help them to make sense of what they are experiencing. This can involve a few things. It can mean encouraging them to dwell or think about the positives (if any) that have come out of their experiences, something which might be useful even if it is only a distraction from emotional distress, or encouraging them to interpret their major losses as learning experiences that provide opportunities for posttraumatic growth (Harvey 2001). This suggests that health professionals may be able to reduce distress among head and neck caregivers if they can help caregivers to obtain something of personal value or significance from their experience of loss and suffering.

Finally, the presence of nonhead and neck cancer specific negative life events as a cause of distress was interesting and not something that we have seen previously reported. The importance of these events likely stems from the significant length of time caregivers in this study were from the point of diagnosis. As time goes on, many survivors are likely to experience an improvement in their condition. As such, the impact of head and neck cancer and its associated caring activities on many, although not all, caregivers are likely to diminish. The profile of head and neck caregivers, however (generally older and from disadvantaged life circumstances (Mehanna et al. 2010, Chen et al. 2014) means that they are likely to continue to experience adverse life events and have limited resources to be able to easily deal with these events. The results here indicate the importance of taking a global perspective on these individuals' lives. Rather than viewing them solely as 'head and neck cancer caregivers', it may be more useful to see head and neck cancer as one traumatic event among many in a difficult life. Several years out from head and neck cancer, the cancer may be a historical event, and other health and social problems may assume much greater urgency. We believe that this is an important point given the emphasis quantitative research places on time since diagnosis as an explanatory variable in head and neck cancer research. Saying that caregivers experience less distress over time (Longacre et al. 2012) may be misrepresenting these caregivers' actual experiences; distress may simply have shifted from one domain of caregivers' lives (cancer) to another (dementia). It would therefore be useful for future research to explicitly examine caregivers' experiences of loss, and also to explore the noncancer related tragedies that they can sometimes experience in their lives.

Limitations of the study include the fact that we did not clinically quantify caregivers' distress, although that was not our objective as we wanted to understand caregivers experiences); and we also did not assess distress in the same individuals at different points in the illness trajectory (although the study included caregivers of relative/friends who were ranged from 1-18 years postdiagnosis). If we did so we might have seen that at different points in this trajectory caregivers were more or less distressed by different factors. Caregivers' demographical characteristics may also have influenced the results. Caregivers in this study were generally older and were caring for patients who were older still. Caregivers of younger patients may be even more distressed than those interviewed for this study (Shahi et al. 2014, Simpson et al. 2015).

\section{Conclusion}

A number of factors can cause head and neck cancer caregivers to become distressed. Six were identified by this study: understandings and fears of illness, lifestyle restrictions, facial disfigurement, financial problems, negative life events and witnessing suffering. Cutting across all of these individual causes of distress was a strong feeling of loss caused by head and neck cancer. Although distress appears to decline with time for many caregivers, some continue to be distressed for years following the patient's diagnosis.

\section{Relevance to clinical practice}

The six distress causing factors identified by this study provide concrete areas that health professionals can target to 
reduce caregivers' distress. For example, health professionals could challenge the associations that caregivers make between head and neck cancer and death. Health professionals can work to increase public awareness of facial disfigurement and head and neck cancer, thereby reducing the stigma associated with the condition. They can facilitate caregivers' access to financial advice services. They can work with caregivers to help them to make sense of their suffering and their experiences of loss. In these ways, professionals might be able to make what at the time seems an unbearable experience for caregivers a little more bearable.

\section{Contributions}

$\mathrm{MB}, \mathrm{PB}, \mathrm{EOS}, \mathrm{AT}, \mathrm{RGH}$ and LS contributed to study design; MB, RM, PH, PB, EOS, AT, RGH and LS contributed to analysis; MB, RM, PH, PB, EOS, AT, RGH and LS contributed to manuscript preparation.

\section{Conflicts of interest}

The authors declare that they have no conflicts of interest.

\section{References}

Balfe M, Brugha R, Smith D, Sreenan S, Doyle F \& Conroy R (2014) Why do young adults with Type 1 diabetes find it difficult to manage diabetes in the workplace? Health \& Place 26, 180-187.

Bond S, Hawkins D \& Murphy B (2014) Caregiver-reported neuropsychiatric symptoms in patients undergoing treatment for head and neck cancer: a pilot study. Cancer Nursing 37, 227235.

Chambers M, Ryan A \& Connor S (2001) Exploring the emotional support needs and coping strategies of family carers. Journal of Psychiatric and Mental Health Nursing 8, 99-106.

Charmaz K (1983) Loss of self: a fundamental form of suffering in the chronically ill. Sociology of Health and Illness 5, 168-195.

Chen S, Liao Lin C, Chang J \& Lai Y (2009) Distressed and care needs in newly diagnosed oral cavity cancer patients receiving surgery. Oral Oncology 45, 815-820.

Chen S, Lai Y, Liao C, Huang B, Lin C \& Fan K (2014) Unmet supportive care needs and characteristics of family carers of patients with oral cancer after surgery. Psychooncology 23, 569-577.

Chou W, Hunt Y, Beckjord E, Moser R \& Hesse B (2009) Social media use in the United States: implications for health communication. Journal of Medical Internet Research 11, e48.

Davis C \& Nolen-Hoeksema S (2001) Loss and meaning: how do people make sense of loss? The American Behavioural Scientist 44, 726-741.
Donnelly M, Anderson L, Johnston B, Watson R, Murphy S, Comber H, McGuigan J \& Murray L (2008) Oesophageal cancer: carer mental health and strain. Psychooncology 17, 1196-1201.

Drabe N, Zwahlen D, Buchi S, Moergeli H, Zwahlen R \& Jenewein J (2008) Psychiatric morbidity and quality of life in wives of men with long-term head and neck cancer. Psychooncology 17, 199-204.

Fletcher B, Cohen M, Schumacher K \& Lydiatt W (2012) A blessing and a curse: head and neck cancer survivors' experiences. Cancer Nursing, 35, 126132.

Fronczek A (2015) A phenomenologic study of family caregivers of patients with head and neck cancers. Oncology Nursing Forum 42, 593-600.

Given B, Given C \& Kozachik S (2001) Family support in advanced cancer. CA: A Cancer Journal for Clinicians 51, 213-231.

Haman K (2008) Psychological distress and head and neck cancer: part 1review of the literature. The Journal of Supportive Oncology 6, 155-163.

Hanratty B, Holland P, Jacoby A \& Whitehead M (2007) Review article: financial stress and strain associated with terminal cancer-a review of the evidence. Palliative Medicine 21, 7595-7607.

Harvey J (2001) The psychology of loss as a lens to a positive psychology. The American Behavioral Scientist 44, 838-853.

Harvey J \& Miller E (1998) Toward a psychology of loss. Psychological Science 9, 429-434.
Jayani R \& Hurria A (2012) Carers of older adults with cancer. Seminars in Oncology Nursing 28, 221-225.

Lee Y, Lin P, Chien C \& Fang F (2015) Prevalence and risk factors of depressive disorders in caregivers of patients with head and neck cancer. Psychooncology 24, 155-161.

Longacre M, Ridge J, Burtness B, Galloways T \& Fang C (2012) Psychological functioning of carers for head and neck cancer patients. Oral Oncology $48,18-25$.

Longacre M, Galloway T, Parvanta C \& Fang C (2015) Medical communication-related informational need and resource preferences among family caregivers for head and neck cancer patients. Journal of Cancer Education 30, 786-791.

Mehanna H, Paleri V, West C \& Nutting C (2010) Head and neck cancer-part 1: epidemiology, presentation and prevention. British Medical Journal, 341, 663-666.

Mohammed N, Walter A, Oijen M, Hulshof $\mathrm{M}$, Bergman J, Anderegg $\mathrm{M}$, Henegouwen M, Henselmans I, Sprangers M \& van Laarhoven $H$ (2015) Burden of spousal caregivers of stage 2 and 3 esophageal cancer survivors 3 years after treatment with curative intent. Supportive Care in Cancer 23, 3589-3598.

Morse J (2000) Determining sample size. Qualitative Health Research 10, 3-5.

Nijboer C, Tempelaar R, Sanderman R, Triemstra M, Spruit R \& Bos G (1999) Determinants of caregiving experiences and mental health of part- 
ners of cancer patients. Cancer 86, 577-588.

Nund R, Ward E, Scarini N, Cartmill B, Kuipers P \& Porceddu S (2014) Carers' experiences of dysphagia in people treated for head and neck cancer: a qualitative study. Dysphagia 29, 450458.

Offerman M, Pruyn J, de Boer M, Ledeboer Q, Busschbach J, Baatenburg R \& der Velden L (2014) Experience of palliative care for patients with head and neck cancer through the eyes of next of kin: impact of an expert center. Head and Neck 36, 1459-1466.

Parker V, Bellamy D, Rossiter R, Graham VM, Britton B, Bennett L \& Giles M (2014) The experiences of head and neck cancer patients requiring major surgery. Cancer Nursing 37, 263-270.

Pearce A, Hanly P, Timmons A, Wlash P, O'Neill C, O'Sullivan E, GoobermanHill R, Thomas A, Gallagher P \& Sharp L (2015) Productivity losses associated with head and neck cancer using human capital and friction cost approaches. Applied Health Economics and Health Policy 13, 359-367.

Penner J, McClement S, Lobchuk M \& Daeninch P (2012) Family members' experiences caring for patients with advanced head and neck cancer receiving tube feeding: a descriptive phenomenological study. Journal of Pain and Symptom Management 44, 563571.

Pitceathlya C \& Maguire P (2003) The psychological impact of cancer on patients' partners and other key relatives: a review. European Journal of Cancer 39, 1517-1524.

Precious E, Haran S, Lowe D \& Rogers S (2012) Head and neck cancer patients' perspectives of carer burden. British Journal of Oral and Maxillofacial Surgery 50, 202-207.

Richardson A, Morton R \& Broadbent E (2015a) Caregivers' illness perceptions contribute to quality of life in head and neck cancer patients at diagnosis. Journal of Psychosocial Oncology 33, 414-432.

Richardson A, Morton R \& Broadbent E (2015b) Psychological support needs of patients with head and neck cancer and their caregivers: a qualitative study. Psychology and Health 30, 1288-1305.

Roing M, Hirsch J \& Holmstrom I (2008) Living in a state of suspension-a phenomenological approach to the spouse's experience of oral cancer. Scandinavian Journal of Caring Sciences 22, 40-47.

Ross S, Mocher C, Ronis-Tobin V, Hermele S \& Ostroff J (2010) Psychosocial adjustment of family carers of head and neck cancer survivors. Supportive Care in Cancer 18, 171-178.

Schaller A, Liedberg G \& Larsson B (2014) How relatives of patients with head and neck cancer experience pain, disease progression and treatment: a qualitative interview study. European Journal of Oncology Nursing 18, 405-410.
Shahi V, Lapid M, Kung S, Atherton P, Sloan J, Clark M \& Rummans T (2014) Do age and quality of life of patients with cancer influence the quality of life of the caregiver? Journal of Geriatric Oncology 5, 331-336.

Simpson G, Dall'Armi L, Roydhouse J, Forstner D, Daher M, Simpson T \& White K (2015) Does resilience mediate carer distress after head and neck cancer? Cancer Nursing 38, 30-36.

Timmons A, Gooberman-Hill R \& Sharp L (2013) 'It's a time in your life when you are most vulnerable': a qualitative exploration of the financial impact of a cancer diagnosis and implications for financial protection in health. Public Library of Science One 8, e77549.

Tong A, Sainsbury P \& Craig J (2007) Consolidated criteria for reporting qualitative research (COREQ): a 32item checklist for interviews and focus groups. International Journal for Quality in Health Care 19, 349. 357.

Vaskill V, Crowe M, Luty S \& Joyce P (2010) Two sides of the same coin: caring for a peson with bipolar disorder. Journal of Psychiatric and Mental Health Nursing 17, 535-542.

Verdonck-de Leeuw I, Eerenstein S, Linden M, Kuik D \& de Bree R (2007) Distress in spouses and patients after treatment for head and neck cancer. The Laryngoscope 117, 238-241. 